\title{
Book Review: U. Sehrt (PR Beratung Sehrt, Germany) and M. Grehl (Umicore AG \& Co KG, Germany) (ed): Precious Materials Handbook
}

\author{
Umicore AG \& Co. KG, Hanau-Wolfgang, Germany, 1st edition, 2012, 576 pages, (ISBN \\ 978-3-8343-3259-2), €89
}

\author{
Christopher W. Corti
}

Published online: 19 March 2013

(C) The Author(s) 2013. This article is published with open access at SpringerLink.com

For those dedicated scientists and researchers interested in the precious metals, the two editions of the EdelmetallTaschenbuch (Precious Metals Pocket Book) published by Degussa (now Umicore) back in 1967 and 1995 have been invaluable as a comprehensive source of a wide range of basic property data as well as a comprehensive guide to their industrial applications. If you need to know the thermal expansion coefficients of Au-Ag alloys, the electroplating of gold, the catalytic properties of the PGMs, the working and manufacture of precious metal alloys plus the spectrum of phase diagrams, chemical, mechanical and physical properties - you will find all you need in these books. For those of us who struggle with the German language, the only downside has been that they were published in German, rather than in English. Neither were they practical 'pocket books' as they were a little too large for such a description!

Imagine my delight to learn that a new, even larger, book by Umicore called the Precious Materials Handbook had been published. Seventeen years on, the world of precious metals has changed somewhat - look at how nanotechnology and gold catalysis have erupted in that time - and there was a need for an updated version. At last it was in English too. But I was somewhat surprised to see it was not simply an updated version of the old Pocket Books but that it is a totally new book, quite different in style, although much of the invaluable property data is still to be found within its pages.

C. W. Corti $(\bowtie)$

COReGOLD Technology, Reading, UK

e-mail: Chris@corti.force9.co.uk
In their preface to the book, Drs Marc Van Sande and Matthias Grehl state that the objective was "to illustrate how metals-based materials contribute to crucial applications. Examples have been selected in line with specific megatrends which have a tremendous bearing on society and the environment." They go on further to discuss three aspects: resource scarcity, more stringent emission control standards and renewable energy solutions.

The Handbook comprises ten chapters plus an appendix, each written by different groups of expert authors, many of whom are employees of Umicore. It is a quality production, well illustrated, and with a glossary and reference list at the end of each chapter.

The first chapter concerns the "Availability of Metals \& Materials" and includes sections on the sustainable use of metals, the significance of special and precious metals, the scarcity debate and trading markets, pricing and metals management. This is a meaty chapter that is wider than just the precious metals, very relevant to today's issues and sets the tone for subsequent ones. It underlines the importance of the precious metals to our modern lifestyle.

Chapter two follows on "Recycling and Loop Concept for a Sustainable Usage" and is a strong discussion on the challenges and opportunities of recycling of precious and other metals faced by society. The technologies involved in refining of the precious metals in their various scrap forms are also covered, along with the associated commercial practices. The chapter concludes with a section on future challenges and requirements.

The third chapter is about "Methods to Develop Advanced Materials" and discusses management of knowledge and 
innovation as well as analytics and modelling in some detail. This will be familiar, useful information to many managers responsible for R \& D and new product development.

Chapter Four is headed simply, "Precious Metals" and may be considered to be the heart of this book. It has ten sections, starting with 'interesting facts', moving on to 'supplies, mining and exploration', then 'primary winning of precious metals', 'refining of gold and silver' and 'refining of the PGMs'. It then moves on to the 'properties of precious metals and alloys'. This includes crystal lattice data, phase diagrams, microstructure and the gamut of chemical, mechanical and physical properties, with a lot of the data presented in tabular form. It is worth noting here that the appendix to the book comprises a series of phase diagrams and thermodynamic data that supports this chapter. This is heartwarming stuff for us metallurgists and materials technologists.

The next section is aimed more at the chemists and covers 'precious metal compounds', particularly precursors as well as inorganic and organic compounds of the precious metals. This is followed by a small section on 'therapeutic agents', particularly the platinum anticancer drugs, and then a larger one on 'precious metal platings for decorative, functional and technical applications'. It covers all precious metals individually and finishes with their use in bonded electrical connections and contacts. A look at the use of precious metals in the glass industry and silver in electrical contacts finish this chapter in a section headed 'Selected applications'.

The fifth chapter concerns "Materials for Heterogeneous Catalysis" and is very comprehensive, covering concepts, materials, characterisation, deactivation and eight further sections on particular applications in the automotive sector. This is essential reading for those involved in pollution control. This is followed by Chapter 6 on "Homogeneous and Industrial Catalysis" which considers principles and several reaction types including carbonylations, alkenes and cross-coupling. A short section on 'Reactions of interest to Umicore' includes the new field of gold catalysis, oxidation catalysts, $\mathrm{C}-\mathrm{H}$ bond functionalisation and immobilised catalysts.

"Materials for Fuel Cells" is the subject of chapter 7 and covers the various types of fuel cell, its application in the automotive sector and fuel processing, an area in which gold catalysis may play a role. This is followed by chapter 8 , "Materials for Photovoltaics", which looks at the market as well as the technologies and materials involved. Chapter 9 moves on to "Advanced Battery Materials" and discusses traditional, Lithium-ion and new battery concepts as well as their recycling.

The last chapter, Chapter 10, is, perhaps, a surprising inclusion in a precious materials handbook since it concerns zinc, a well-known base metal. Titled "Zinc - Facts and Applications", it covers the properties, minerals and extraction metallurgy of zinc followed by a section on its applications. Clearly its roles in corrosion protection feature strongly here, as does its use in batteries. Interesting as it is, it seems out of place and I wonder why it is included in this book.

In summary, this is a good, solid reference book for all those involved with the precious metals and their applications. It is well presented and is a book one will dip into rather than reading from cover to cover. It cannot cover all aspects in great depth but serves as a good starting point for those entering into new areas. However, it acts as an excellent overview and source of specific property data for those used to the old Edelmetall-Taschenbuch as a source of property data. It is a more than worthy replacement and covers new important aspects such as sustainability, which increasingly affect our way of life. I believe it will serve our industry well and commend it to all with an interest in the precious metals. An essential book on one's desk. I congratulate all the authors involved on a book well done.

Open Access This article is distributed under the terms of the Creative Commons Attribution License which permits any use, distribution, and reproduction in any medium, provided the original author(s) and the source are credited. 